In these determinations a pure product need not be used-any hydrocarbon boiling tetween $100^{\circ}$ and $200^{\circ}$ will serve, the precaution being taken, however, to determine how much water it contains, and allowing for the same.

Recently a German patent No. I30,295 was granted for determining water in substances by adding a higher boiling liquid thar: water and one that does not mix with it. It is to be regretted that these simple laboratory methods should be made the subjects of patents, and it is difficult to understand the object of taking such a patent; but in this case it would be invalid in the United States, as the method has been used for a long time at different works.

LABORATORY, BARRETT MANUFACT'RING Co.

\title{
A PROCESS FOR MAKING AVAILABLE PHOSPHATES.
}

BY C. H, DEMPWOLF, JR,

Received May 29, 1903.

A NUMBER of processes for the manufacture of available phosphates by means other than that of sulphuric acid have been recently proposed. From among these processes the following have been taken as seeming of the most importance.

G. F. Wilson ( $186 \mathrm{I}$ ) patented a process, which consists in treating ground mineral phosphates, bone-black, etc., with fused sodium bisulphate and steam under high pressure. A double decomposition of the tricalcium phosphate into calcium sulphate and sodium phosphate is claimed for the process, thus leaving the phosphoric acid in a form more available as a plant food. The source of the bisulphate is the waste product obtained in the manufacture of sulphuric and hydrochloric acids. ${ }^{1}$

G. A. Liebig ( 1881 ) proposed a process in which phosphates are mixed with carbon and subjected to a high heat. The proportions given are two parts of the phosphate to one of carbon. ${ }^{2}$

The process of Brunner and Zanner consists in treating the finely powdered natural phosphates with a solution of sodium bisulphate. After filtration, the liquid contains the calcium acid phosphate, which is then precipitated by an excess of lime. ${ }^{3}$

1 U. S. Patent 75,325 .

2 U. S. Patent $24 I, 868$.

3 Moniteur Srientifique, 1892, p. 100, and Eng. Patent 2,389, Feb. 8, 1892 . 
A method of making hydrated phosphate of alumina soluble in ammonium citrate was proposed by Pillon Freres and Buffet in 1892. This process is simply a dehydration by the action of heat and is used in the manufacture of Redonda phosphate. ${ }^{1}$

Stephen L. Goodale obtained a United States patent on a similar process in 1893 . Morse has shown, however, that the dehydrated phosphate of alumina, as sold under the name of Redonda phosphate, absorbs water very rapidly and reverts to the hydrated or insoluble form, this being its probable action in the soil. ${ }^{2}$

C. H. Knoop, by heating mixtures of natural phosphates with alkaline silicates or materials capable of forming these silicates, to a red heat, obtained a complex alkaline phosphate, in which 99 per cent. of the phosphoric acid is soluble in Wagner's citrate solution. The following charges are given as yielding good results: ${ }^{3}$

Parts.

Tricalcium phosphate $\ldots \ldots \ldots \ldots \ldots \ldots \ldots \ldots \ldots \ldots \ldots$ I0

Calcium carbonate $. \ldots \ldots \ldots \ldots \ldots \ldots \ldots \ldots \ldots \ldots \ldots, 80$

Sodium sulphate.......................... 60

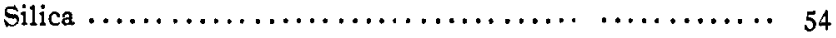

Tricalcium phosphate...................... 100

Calcium carbonate......................... 36

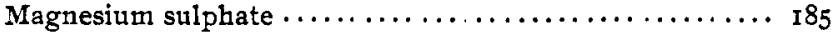

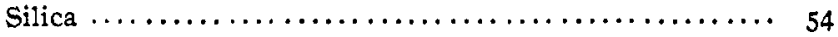

J. G. Wiborgh, of Stockholm, obtained a patent in the United States on a process of igniting apatite with alkaline carbonates or hydroxides. It consists in pulverizing the apatite and mixing it with carbonate of sodium or potassium or with sodium or potassium hydroxides, and subsequently heating the mixture to a red or yellow heat. A tetracalcium sodium (or potassium) phosphate is formed according to the following equation:

${ }_{3} \mathrm{Ca}_{3}\left(\mathrm{PO}_{4}\right)_{2} \cdot \mathrm{CaF}_{2}+{ }_{3} \mathrm{Na}_{2} \mathrm{CO}_{3}=\mathrm{Ca}_{10} \mathrm{Na}_{4} \mathrm{P}_{6} \mathrm{O}_{27}+2 \mathrm{NaF}+3 \mathrm{Co}_{2}$

This double phosphate is readily soluble in ammonium citrate. ${ }^{4}$

A more recent patent of Wiborgh and Palmaer (I903) describes an electrolytic process for the manufacture of soluble phosphates. Apatite or other phosphate is placed in an electrolytic cell with a salt solution adapted to liberate an acid at the anode, forming a soluble salt with lime, while at the cathode a basic hydroxide is

1 Moniteur Scientifique, 1892 , p. 210 , and Eng. Patent 6,023, Nov. 30, 1892.

2 This Journal, r903, p. 280.

3 Centralblatt, 1899 , p. 1052.

4 U. S. Patent 601,089 . 
formed, the acid dissolving the phosphate and precipitating the same in the alkaline liquid of the cathode. ${ }^{1}$

Shutt, in a paper on the action of ground mineral phosphates as a fertilizer, ${ }^{2}$ describes experiments on the fusion of apatite with sodium sulphate and sodium bisulphate. It was found that when apatite is fused with sodium sulphate, 35 per cent. of the total phosphoric acid in the product becomes soluble in a 2 per cent. citric acid solution. When the bisulphate is used, 50 per cent. of the total phosphoric acid is soluble.

The use of a I per cent. citric acid solution as a means of determining the availability of phosphates as a plant food is customary in England. The results obtained by Shutt are probably higher than would be given by a I per cent. citric acid solution or the neutral solution of ammonium citrate, as adopted by the Association of Official Agricultural Chemists.

Baskerville noted that when natural phosphates were heated with alkaline salts, such as sodium sulphide, sodium nitrate, sodium carbonate and sodium sulphate, a large proportion of the phosphoric acid became citrate-soluble. The rock contained 35 per cent. $\mathrm{Ca}_{3}\left(\mathrm{PO}_{4}\right)_{2}$ and was mixed with sodium carbonate in the proportion of 4 of rock to I of carbonate. The mixture was heated to a red heat and gave a 75 to 90 per cent. yield, depending upon the temperature and the duration of heating. The percentage of water-soluble phosphoric acid was not notably increased. ${ }^{3}$

\section{EXPERTMENTAL.}

This work was undertaken with a view to the utilization of niter cake, the by-product from the manufacture of sulphuric acid, and at the same time the production of an available phosphate. This niter cake is the residue from the treatment of sodium nitrate with sulphuric acid and is composed mainly of sodium bisulphate with a small percentage of the normal sulphate. The niter cake used in these experiments was found to contain $\mathrm{NaHSO}_{4}, 86.93$ per cent.; $\mathrm{Na}_{2} \mathrm{SO}_{4}, 9.72$ per cent.

EXPERIMENTS WITH BONE ASH.

'Twenty grams of ground bone-ash containing 40.16 per cent. insoluble phosphoric acid was mixed with an equal quantity of niter cake and heated in a porcelain crucible for thirty minutes

1 C. S. Patent 707,886 and this Journal, 1903.

2 Chem. Nere's (1896), p. 4.

${ }^{8}$ J. Soc. Chem. Ind, December, Igor. 
with the blast-lamp. The mixture before heating contained 20.08 per cent. phosphoric acid. A second charge was run at the same time, using 20 grams bone-ash, and 20 grams niter cake, with the addition of 4 grams charcoal. This mixture was heated for the same length of time and at the same temperature as in the first case.

The analyses of the sintered masses may be stated as follows:1

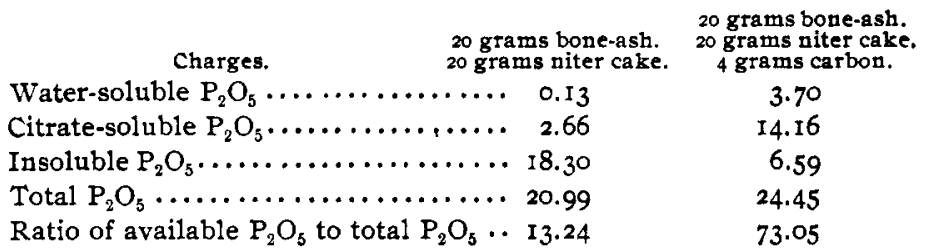

This increase in the percentage of available phosphoric acid is due mainly to the formation of the double phosphate of calcium and sodium $\left(\mathrm{Ca}_{10} \mathrm{Na}_{4} \mathrm{P}_{8} \mathrm{O}_{27}\right)$, which is soluble in ammonium citrate solution and to a slight extent to the fact that tricalcium phosphate is more soluble in water containing alkaline salts than in pure water. Other double phosphates of calcium and sodium have been prepared, and Baer mentions a calcium sodium pyrophosphate having the formula $\mathrm{CaNa}_{2} \mathrm{P}_{2} \mathrm{O}_{7} \cdot 4 \mathrm{H}_{2} \mathrm{O}^{2}$ The formula as given by Wiborgh corresponds to the tetracalcium phosphate as present in basic or Thomas slag and is probably the one which is formed under these conditions.

The analyses show that when carbon was used, the ratio of available phosphoric acid to total phosphoric acid was increased from I3.24 to 73.05 per cent. The sodium bisulphate was used in excess over the amount necessary to form the double salt $\mathrm{Ca}_{10} \mathrm{Na}_{4} \mathrm{P}_{8} \mathrm{O}_{27}$, while the carbon used was the calculated amount necessary to reduce the sodium acid sulphate to sodium sulphide. When sodium bisulphate is heated, it loses water according to the equation

$$
2 \mathrm{NaHSO}_{4}=\mathrm{Na}_{2} \mathrm{~S}_{2} \mathrm{O}_{7}+\mathrm{H}_{2} \mathrm{O} \text {. }
$$

This pyrosulphate, at a somewhat higher temperature, loses sulphur trioxide and the normal sulphate is formed,

$$
\mathrm{Na}_{2} \mathrm{~S}_{2} \mathrm{O}_{7}=\mathrm{Na}_{2} \mathrm{SO}_{4}+\mathrm{SO}_{3} \text {. }
$$

1 The methods of analysis used in these experiments were those adopted by the Association of official Agricultural Chemists and described in wiley's "Principles and Practice of Agricultural Analysis," vol. II.

2 Pogg. Ann., 75, p. I59. 
The action of the carbon is to reduce the normal sulphate thus formed to sodium sulphide according to the following reaction:

$$
\mathrm{Na}_{2} \mathrm{SO}_{4}+{ }_{4} \mathrm{C}=\mathrm{Na}_{2} \mathrm{~S}+{ }_{4} \mathrm{CO} \text {. }
$$

It is probable that some polysulphides are also formed.

\section{EXPERIMENTS WITH PFIOSPEATE ROCK.}

Similar experiments were made, using a natural Florida phosphate containing 30.28 per cent. $\mathrm{P}_{2} \mathrm{O}_{3}$, of which $\mathrm{I} .30$ per cent. was citrate-soluble. These charges were heated exactly as in the preceding case and yielded the following analyses:

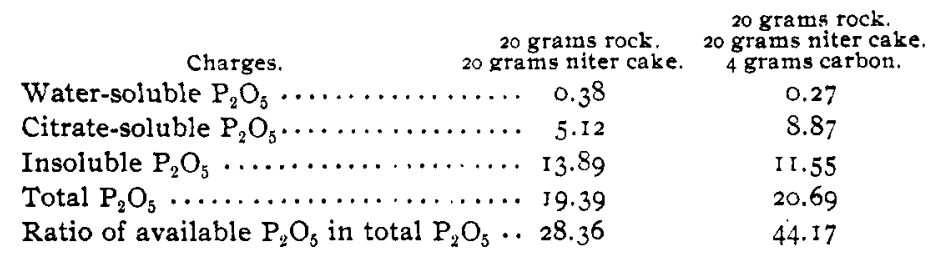

Here the increase in yield, due to the action of the carbon in forming sodium sulphide, is not so large as when bone-ash was used.

The effect of heat alone upon the phosphate rock was determined by igniting 20 grams of the rock for thirty minutes in the blast. The analysis, after ignition, shows a small increase of citratesoluble phosphoric acid, due probably to the dehydration of the ferric and aluminum phosphates present.

\begin{tabular}{|c|c|c|}
\hline & $\begin{array}{l}\text { Analysis of rock } \\
\text { before ignition. }\end{array}$ & $\begin{array}{l}\text { Analysis of rock } \\
\text { after ignition. }\end{array}$ \\
\hline Total $\mathrm{P}_{2} \mathrm{O}_{5} \ldots \ldots \ldots$ & $\cdots \quad 30.28$ & 31.82 \\
\hline Citrate-soluble $\mathrm{P}_{2} \mathrm{O}_{5}$ & ... I.3O & 3.27 \\
\hline
\end{tabular}

A mixture of 10 grams phosphate rock and Io grams sodium sulphide, heated as described above, gave the following analysis:

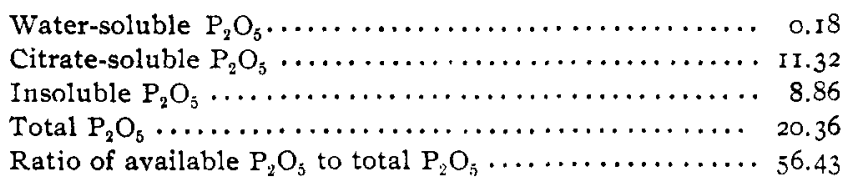

It was believed that the above results could be improved upon, and the following experiments were made in order to determine the effect of temperature, duration of heating and the proportion of ingredients in the mixture upon the amount of available phosphoric acid in the product. 
In order to determine the most effective temperature, mixtures of ro grams phosphate rock, Io grams niter cake and 2 grams charcoal were heated for thirty minutes at temperatures of $830^{\circ}$, $1090^{\circ}$ and $1200^{\circ} \mathrm{C}$. and for one hour at $830^{\circ}$ and $1090^{\circ} \mathrm{C}$. The analysis of the products are shown in the following table:

\begin{tabular}{|c|c|c|c|c|c|}
\hline \multirow[b]{2}{*}{ Temperature.........} & \multicolumn{3}{|c|}{30 minutes. } & \multicolumn{2}{|c|}{ I hour. } \\
\hline & $830^{\circ}$ & $1090^{\circ}$ & $1200^{\circ}$ & $830^{\circ}$ & $\log 0^{\circ}$ \\
\hline Water-soluble $\mathrm{P}_{2} \mathrm{O}_{5} \ldots \ldots \ldots$ & 0.16 & 0.33 & 0.24 & 0.30 & 0.25 \\
\hline Citrate-soluble $\mathrm{P}_{2} \mathrm{O}_{5} \ldots \ldots \ldots$ & 8.26 & I0.DO & 12.55 & 8. I9 & 13.57 \\
\hline Insoluble $\mathrm{P}_{2} \mathrm{O}_{5}, \ldots \ldots \ldots \ldots$ & $1 \mathrm{I} .8_{3}$ & 9.54 & 8.77 & 12.05 & $7 \cdot 33$ \\
\hline $\begin{array}{l}\text { Total } \mathrm{P}_{2} \mathrm{O}_{5} \ldots \ldots \ldots \ldots \ldots \ldots \\
\text { Ratio of available } \mathrm{P}_{2} \mathrm{O}_{5} \text { to }\end{array}$ & 20.25 & I9.87 & 21.56 & 20.54 & 2I.I 5 \\
\hline total $\mathrm{P}_{2} \mathrm{O}_{5}, \ldots \ldots \ldots \ldots$ & $41.5^{8}$ & $5 r .98$ & 59.32 & 41.33 & 65.34 \\
\hline
\end{tabular}

These results indicate that the amount of available phosphoric acid is increased by an increase in temperature and duration of heating. The charges heated to $830^{\circ}$ and $1090^{\circ}$ were very porous and easily pulverized, while the charge heated to $1200^{\circ}$ for thirty minutes was partly fused and difficult to break.

Mixtures containing 10 grams phosphate rock and varying proportions of $4,6,8$ and to grams niter cake, with carbon sufficient in each case to reduce the bisulphate, were made up and heated for one hour at a temperature of $1090^{\circ} \mathrm{C}$. The results of the analyses of these products are as follows:

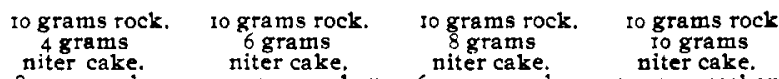

Water-soluble $\mathrm{P}_{2} \mathrm{O}_{5}$ O.I2

Titer cake, niter cake.

Citrate-soluble $\mathrm{P}_{2} \mathrm{O}_{5} 16.53$

Insoluble $\mathrm{P}_{2} \mathrm{O}_{5} \cdots 10.84$

Total $\mathrm{P}_{2} \mathrm{O}_{5} \ldots \ldots \cdots 27.49$

Ratio of available

\begin{abstract}
0.19
\end{abstract}
15.74

9.13

25.06

$63 \cdot 56$
0.28

I 2.53

8.96

21.77

58.84 niter cake.

0.25

13.57

$7 \cdot 33$

21.15

$65 \cdot 34$

The differences shown above between the ratios of available phosphoric acid to total phosphoric acid are not very great, the best yield being obtained with the mixture containing Io, Io and 2 parts respectively of rock, niter cake and carbon. The product from this charge contained considerable excess of sodium sulphide, which, on exposure to air, oxidized to sulphate and absorbed water very rapidly. One gram of this phosphate was exposed under a bell-jat for several days to an atmosphere saturated 
with moisture. The increase in weight due to oxidation and absorption of water was noted as follows: After 24 hours, 0.1856 gram; after 48 hours, 0.2148 gram; after 72 hours, 0.2254 gram.

One gram of the phosphate from the mixture Io grams rock, 4 grams niter cake and 0.8 gram carbon was exposed in a similar manner, the absorption in this case being considerably less than the above figures. The increase in weight for three days was. after 24 hours, 0.0384 gram; after 48 hours, 0.0522 gram; after 72 hours, 0.0550 gram.

A modification of Knoop's charge, using a proportional quantity of niter cake in place of the normal sodium sulphate, was tried, but with little success. The charge was made up by mixing 20 grams phosphate rock, 10.6 grams calcium carbonate, 16 grams niter cake and 6.6 grams silica, and heated for a half hour at a temperature of $1090^{\circ} \mathrm{C}$.

Analysis:

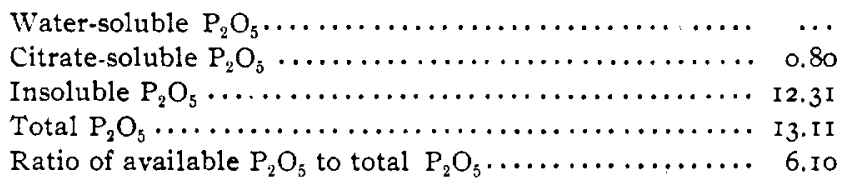

A double phosphate and silicate of lime corresponding to the formula $\mathrm{Ca}_{3}\left(\mathrm{PO}_{4}\right)_{2} \cdot \mathrm{CaSiO}_{4}$ would be formed under these conditions and does not seem to be soluble to any great extent in the neutral citrate of ammonia.

A method of treating the phosphate rock with the niter cake in solution was more successful than any of the above-described experiments. Twenty grams of the ground rock and twenty grams of niter cake were mixed in a beaker-glass and water added to form a thin paste. This was allowed to stand for four weeks with frequent addition of water and stirring, at the end of which time the water was allowed to evaporate and the mixture dried in the air. An analysis of the product thus obtained was as follows:

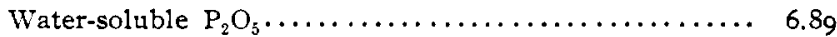

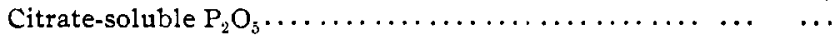

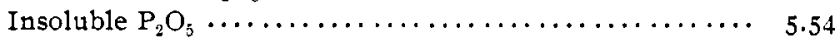

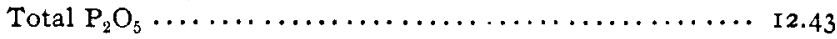

Ratio of available $\mathrm{P}_{2} \mathrm{O}_{5}$ to total $\mathrm{P}_{2} \mathrm{O}_{5} \ldots \ldots \ldots \ldots \ldots \ldots \ldots \ldots \ldots \ldots+43$ 
In this case no citrate-soluble phosphoric acid was formed, all of the available phosphate being soluble in water. The tricalcium phosphate, being somewhat soluble in water containing alkaline salts, neutralizes the acidity of the bisulphate according to the equation

$\mathrm{Ca}_{3}\left(\mathrm{PO}_{4}\right)_{2}+4 \mathrm{NaHSO}_{4}=\mathrm{CaH}_{4}\left(\mathrm{PO}_{4}\right)_{2}+2 \mathrm{Na}_{2} \mathrm{SO}_{4}+\mathrm{CaSO}_{4} \cdot{ }^{1}$

CONCLUSIONS.

The sulphuric acid industry being so closely allied to the manufacture of fertilizers, it would seem from the foregoing work that it is possible to utilize the sodium bisulphate, niter cake, to good effect in the production of an available phosphate. The cost of producing acid phosphate on a large scale by means of sulphuric acid is very low and any process, even though an auxiliary one, for the production of the same phosphate must necessarily be a cheap one. $^{2}$ The method of heating mixtures of niter cake, phosphate rock and carbon would probably be more expensive than the present one for any but a cheap low-grade phosphate rock. Furthermore, there is a general prejudice against the use of citratesoluble or so-called "reverted phosphoric acid", although it has been given the same value as that soluble in water by the various experiment stations of this country.

It is believed by agricultural chemists that when an acid phosphate, containing the various forms of phosphoric acid is applied to a soil containing iron and alumina, the soluble parts of the compound tend to become fixed by union with such bases or by precipitation as $\mathrm{Ca}_{2} \mathrm{H}_{2}\left(\mathrm{PO}_{4}\right)_{2}{ }^{3}$

The method of treating the pulverized phosphate with a solution of niter cake promises to be more successful, since the available phosphoric acid in the product constitutes 55.43 per cent. of the total phosphoric acid and is completely soluble in water. By finer grinding of the rock, it may be possible to increase the yield, and the time four weeks may be longer than is necessary to complete the reaction.

1 It is possible that some sodium phosphate may be formed in the above process.

2 A 14 per cent. acid phosphate can be made for about $\$ 7$ per ton.

3 wiley's "Principles and Practice of Agricultural Chemical Analysis," vol. II., p. 140. 